\title{
Infusions from Thymus vulgaris L. treated at different gamma radiation doses: effects on antioxidant activity and phenolic composition
}

Running title: Gamma irradiation effects on antioxidants of thyme infusions

Eliana Pereira $^{\mathrm{a}, \mathrm{b}}$, Lillian Barros ${ }^{\mathrm{a}, \mathrm{c}}$, Amilcar L. Antonio ${ }^{\mathrm{a}, \mathrm{d}}$, Sandra Cabo Verde ${ }^{\mathrm{d}}$, Celestino Santos-Buelga ${ }^{\mathrm{b}}$, Isabel C.F.R. Ferreira, ${ }^{\mathrm{a},}$

${ }^{a}$ Centro de Investigação de Montanha (CIMO), ESA, Instituto Politécnico de Bragança, Campus de Santa Apolónia, 1172, 5300-253 Bragança, Portugal.

${ }^{b}$ GIP-USAL, Facultad de Farmacia, Universidad de Salamanca, Campus Miguel de Unamuno, 37007 Salamanca, Spain.

${ }^{c}$ Laboratory of Separation and Reaction Engineering - Laboratory of Catalysis and Materials (LSRE-LCM), Polytechnic Institute of Bragança, Campus de Santa Apolónia, 1134, 5301-857 Bragança, Portugal.

${ }^{d}$ Centro de Ciências e Tecnologias Nucleares (C2TN), Instituto Superior Técnico, Universidade de Lisboa, E.N. 10, 2695-066 Bobadela, Portugal.

*Author to whom correspondence should be addressed (e-mail: iferreira@ipb.pt, telephone +351273303219 , fax +351273325405$)$. 


\begin{abstract}
The use of ionizing radiation dates back to many years ago, and is accredited for application in different foods with several purposes. It has been increasingly used in many countries for the treatment of aromatic plants. Thymus vulgaris L. (thyme) is a plant commonly used by food, pharmaceutical and cosmetic industries representing a natural source of several bioactives such as phenolic compounds. The aim of this work was to evaluate the effects of gamma radiation on the antioxidant activity (measured through the free radical scavenging activity, reducing power and lipid peroxidation inhibition) and phenolic compounds profile (obtained by HPLC-DAD-ESI/MS) of infusions prepared from irradiated thyme. The results showed that gamma irradiation at the dose of $10 \mathrm{kGy}$ improved the free radical scavenging activity, reducing power and lipid peroxidation inhibition capacity of the studied infusions, while increasing significantly the concentrations of methyleriodictyol- $O$-pentosylhexoside, luteolin-7-Oglucoside, eriodictyol and total flavonoids content. Thus, gamma radiation could be considered as a suitable treatment to be used in Thymus vulgaris L., herein validated for its bioactive parameters.
\end{abstract}

Keywords: Gamma radiation; Thyme; Infusions; Antioxidant activity; Phenolic compounds. 


\section{Introduction}

Irradiation is a physical decontamination and preservation method, which processes the food at room temperature (Alothman, Bhat \& Karim, 2009). It is used by the industry for different purposes, such as disinfestation, shelf life extension, decontamination and improvement of product quality (Singh \& Datta, 2010). Despite being an increasingly popular technology, the number of irradiated foods is very low, even in countries where this preservation process is permitted. The main reasons are not only related with the high cost of the equipment but, especially, with the lack of acceptance by consumers (Sádecká, 2007; Roberts, 2014). The irradiation can be applied by using gamma rays, electron beams or X-rays, each one with different properties and comprising technological advantages and disadvantages (Alothman, Bhat \& Karim, 2009).

Gamma radiation has been applied to several matrices, including mushrooms and aromatic plants, being verified that guarantees the quality of the products for the authorized radiation doses (Fernandes, Antonio, Barreira, Oliveira, Martins \& Ferreira, 2012; Kausar, Akram \& Kwon, 2013; Pereira, Antonio, Barreira, Barros, Bento \& Ferreira, 2015b). It is also characterized by its high penetration ability, being effective in irradiation of large volume foods (IAEA, 2002). Irradiation has been applied to aromatic and medicinal plants with a maximum permitted dose of $10 \mathrm{kGy}$ in Europe; this treatment allows the decontamination of such matrices, while maintaining their chemical, nutritional and organoleptic properties (EU, 1999).

For a long period of time, the plants were almost the only source of therapeutic agents for humans. Indeed plants are natural sources of phytochemicals, especially polyphenols, which have been related to the prevention of chronic diseases and improved health quality (Zhang et al., 2011; Hayta, Polat \& Selvi, 2014). Presently, plants continue being the main sources of substances for drug development by the 
pharmaceutical industry (Carvalho, Costa \& Carnelossi, 2010; Caleja et al., 2015). Several studies have been performed in order to test the effects of irradiation on phytochemicals present in dried plants, and in favorable conditions (irradiation source, dose, humidity, etc.) the antioxidant potential of the species can be increased (Alothman, Bhat and Karim, 2009). The intention of these studies is to follow the process from the irradiation until the consumer and to study the impact of this industrial process on the main components of herbal infusions (DeRutier and Dwyer, 2002)

Thyme (Thymus vulgaris L.) is an herbaceous and perennial aromatic plant belonging to the Lamiaceae family, commonly consumed as herbal infusion and as a condiment and spice (flavoring agent) (Balladin \& Headley, 1999; Helmy, Farrag \& Hasaballah, 2015). It is one of the most cultivated herbs of Thymus genus, being used in food, pharmaceutical and cosmetic industries. It is listed in current editions of the European Pharmacopoeia, US Pharmacopeia and other official papers (Damianova, Tasheva, Stoyanova \& Damianov, 2008; Gavarić et al., 2015), exhibiting carminative, antispasmodic, antitussive, expectorant, bactericidal, antihelmintic and astringent effects. Traditionally, the herb has been used for the treatment of dyspepsia, chronic gastritis and diseases of the upper respiratory tract (Fecka \& Turek, 2008; Helmy, Farrag \& Hasaballah, 2015). It has also been reported that thyme infusions are low caloric beverages (Pereira, Barros \& Ferreira, 2015a), while containing high levels of phenolic compounds with antioxidant properties (Martins, Barros, Santos-Buelga, Silva, Henriques \& Ferreira, 2015).

The aim of the present work was to go further on the study of antioxidant activity and phenolic composition of thyme, previously reported (Brandstetter et al., 2009; Martins et al., 2015; Pereira et al., 2016), evaluating the effects of gamma irradiation on antioxidant potential and phenolic composition of infusions prepared from non- 
irradiated (0 kGy) and irradiated samples of thyme with 1 and $10 \mathrm{kGy}$. These doses where chosen since $1 \mathrm{kGy}$ guarantees insects' disinfestation and $10 \mathrm{kGy}$ is the highest dose permitted by the EU legislation that allows also microbiological decontamination (EU, 1999). The obtained results will assess if the expected benefits of these beverages are maintained after the application of this decontamination/preservation technique.

\section{Materials and methods}

\subsection{Standards and Reagents}

Acetonitrile 99.9\% was of HPLC grade from Fisher Scientific (Lisbon, Portugal). Phenolic compound standards (apigenin-6- $C$-glucoside, caffeic acid, luteolin-7-Oglucoside, naringenin, quercetin-3-O-rutinoside and rosmarinic acid) were from Extrasynthese (Genay, France). Trolox (6-hydroxy-2,5,7,8-tetramethylchroman-2carboxylic acid) was purchased from Sigma (St. Louis, MO, USA) and 2,2-diphenyl-1picrylhydrazyl (DPPH•) was obtained from Alfa Aesar (Ward Hill, MA, USA). $\beta$ Carotene and linoleic acid were acquired from Sigma-Aldrich (St. Louis, Missouri, USA) and Tween 80 from Panreac (Barcelona, Spain). All other solvents and reagents were acquired from scientific retailers. Ferrous ammonium sulfate(II) hexahydrate, sodium chloride and sulfuric acid, all with PA purity, were purchased from Panreac S.A. (Barcelona, Spain), in order to prepare the acid aqueous Fricke dosimeter solution. Water was treated in a Milli-Q water purification system (TGI Pure Water Systems, Greenville, SC, USA).

\subsection{Samples and samples irradiation}

The samples (dry leaves of Thymus vulgaris L.) were provided by a local producer (Pragmático Aroma Lda, Alfândega da Fé, Bragança, Portugal), and divided in three 
groups: control (non-irradiated), 1 (irradiated at $1 \mathrm{kGy}$ ) and 2 (10 kGy). Each group consisted of three samples, each one with $40 \mathrm{~g}$ of dry material, with a total amount of $120 \mathrm{~g}$ for each group.

A gamma radiation equipment (Precisa 22, Graviner Manufacturing Company Ltd., UK) with four ${ }^{60} \mathrm{Co}$ sources, with a total activity $140 \mathrm{TBq}(3.77 \mathrm{kCi})$, was used for sample irradiations, in May 2015. During the irradiation procedure, the dose and dose rate were estimated using Amber Perspex (Batch X, from Harwell Company, Didcot,

Oxfordshire, UK) and Fricke reference dosimeters, respectively (Pereira, Antonio, Barreira, Barros, Bento \& Ferreira, 2015b; ASTM, 1992).

The estimated radiation doses for groups 1 and 2 were $1.2 \pm 0.1 \mathrm{kGy}$ and $10.4 \pm 0.9$ kGy, respectively. For simplicity, the values $1 \mathrm{kGy}$, and $10 \mathrm{kGy}$ are considered for presentation and discussion of the results. The dose rate and dose uniformity ratio $\left(\mathrm{D}_{\max } / \mathrm{D}_{\min }\right)$ were 1.7 and $1.2 \mathrm{kGy} / \mathrm{h}$, respectively.

\subsection{Infusions preparation}

The infusions were prepared according to Pereira, Antonio, Barreira, Barros, Bento \& Ferreira, (2015b) and were obtained from dried plants irradiated. Briefly, $1 \mathrm{~g}$ of the sample was added to $200 \mathrm{~mL}$ of boiling distilled water (after being taken out from the heating source) and left to stand at room temperature for $5 \mathrm{~min}$, and then filtered under reduced pressure.

\subsection{Total phenolic content, total flavonoid content and in vitro antioxidant activity}

The Folin-Ciocalteu method was used to estimate total phenolic content following a method explained by Wolfe, Wu and Liu (2003) and total flavonoid content were determined by a colorimetric assay using aluminum trichloride, as previously described 
by Jia, Tang and $\mathrm{Wu}$ (2013). The results were expressed as mg of gallic acid equivalents (GAE) per $\mathrm{mL}$ of infusion for total phenolic content and as $\mathrm{mg}$ of $(+)$-catechin equivalents $(\mathrm{CE})$ per $\mathrm{mL}$ of infusion for total flavonoid content.

DPPH radical-scavenging activity was evaluated by using an ELX800 microplate reader (Bio-Tek Instruments Inc., Winooski, VT, USA), and calculated as a percentage of DPPH discoloration using the formula: $\left[\left(A_{D P P H}-A_{S}\right) / A_{D P P H}\right] \times 100$, where $A_{S}$ is the absorbance of the solution containing the sample at $515 \mathrm{~nm}$, and $A_{D P P H}$ is the absorbance of the DPPH solution (Pereira, Barros \& Ferreira, 2013).

Reducing power was evaluated by the capacity to convert $\mathrm{Fe}^{3+}$ into $\mathrm{Fe}^{2+}$, measuring the absorbance at $690 \mathrm{~nm}$ in the microplate reader (Pereira, Barros \& Ferreira, 2013). Inhibition of $\beta$-carotene bleaching was evaluated through the $\beta$-carotene/linoleate assay; the neutralization of linoleate free radicals avoids $\beta$-carotene bleaching, the reaction was measured at $470 \mathrm{~nm}$ in a spectrophotometer (AnalytikJena, Jena, Germany) and $\beta$ carotene bleaching inhibition (\%) was calculated using the equation: ( $\beta$-carotene absorbance after $2 \mathrm{~h}$ of assay/initial absorbance) $\times 100$ (Amarowicz et al., 2004).

Lipid peroxidation inhibition in porcine brain homogenates was evaluated by the reduction of thiobarbituric acid reactive substances (TBARS); the colour intensity of the malondialdehyde-thiobarbituric acid (MDA-TBA) was measured by its absorbance at $532 \mathrm{~nm}$; the inhibition ratio (\%) was calculated using the formula: $[(\mathrm{A}-\mathrm{B}) / \mathrm{A}] \times 100 \%$, where A and B were the absorbance of the control and the sample solution, respectively (Fernandes et al., 2013).

The results were then converted to $\mathrm{EC}_{50}$ values $(\mathrm{mg} / \mathrm{mL})$ by using the graphs of the antioxidant activity percentage or absorbance at $690 \mathrm{~nm}$ (in the case of reducing power assay) against the extract concentration. Trolox was used as positive control. 


\subsection{Analysis of individual phenolic compounds}

The aqueous preparations (infusions) obtained above were filtered through a $0.45 \mu \mathrm{m}$ Whatman syringe filter and transferred to an amber HPLC vial for chromatographic injection. The analysis was performed in an HPLC equipment (Agilent Technologies, Santa Clara, CA, USA) with a double online detection in a diode array detector (DAD), using with 280, 330 and $370 \mathrm{~nm}$ as preference wavelengths, and a mass spectrometer (MS) equipped with an ESI source and a triple quadrupole-ion trap mass analyser, which was connected to the HPLC system via the DAD cell outlet. The DAD was coupled to an HP Chem Station (rev. A.05.04) and the MS was controlled by the Analyst 5.1 software. The separation was achieved using a Spherisorb S3 ODS-2 $\mathrm{C}_{18}$ column $(3 \mu \mathrm{m}, 4.6 \times 150 \mathrm{~mm})$ thermostatted at $35^{\circ} \mathrm{C}$, using a gradient elution with the following solvents: $0.1 \%$ formic acid in water (A) and acetonitrile (B). The elution gradient was $15 \%$ B for 5 min, $15 \%$ B to $20 \%$ B over 5 min, $20-25 \%$ B over 10 min, 25$35 \%$ B over $10 \mathrm{~min}, 35-50 \%$ B for $10 \mathrm{~min}$, and re-equilibration of the column (10 min), using a flow rate of $0.5 \mathrm{~mL} / \mathrm{min}$, as previously described by Barros et al. (2013). The MS detector was programmed for recording in two consecutive modes: Enhanced MS (EMS), employed to record full scan spectra, and enhanced product ion (EPI) analysis. Air (zero graded) was used as the nebulizer gas (30 psi) and turbo gas for solvent drying (400 $\left.{ }^{\circ} \mathrm{C}, 40 \mathrm{psi}\right)$. Nitrogen functioned as the curtain (20 psi) and collision gas (medium). The ion spray voltage was set at $-4500 \mathrm{~V}$ and spectra were recorded in negative ion mode between $\mathrm{m} / \mathrm{z} 100$ and 1700 . The settings used were: declustering potential (DP) $450 \mathrm{~V}$, entrance potential (EP) $-6 \mathrm{~V}$, collision energy (CE) $-10 \mathrm{~V}$. EPI mode was performed in order to obtain the fragmentation pattern of the parent ion(s) in the previous scan using the following parameters: DP $-50 \mathrm{~V}, \mathrm{EP}-6 \mathrm{~V}, \mathrm{CE}-25 \mathrm{~V}$, and collision energy spread (CES) $0 \mathrm{~V}$. Compounds were tentatively identified comparing 
the obtained information (retention times, UV-vis and mass spectra) with available data reported in the literature and by comparison with standard compounds, when available. For the quantification a calibration curve for each available phenolic standard (apigenin6- $C$-glucoside, caffeic acid, luteolin-7-O-glucoside, naringenin, quercetin-3-Orutinoside, rosmarinic acid) was constructed based on the UV signal (maximum wavelength of absorption of each standard compound). For the identified phenolic compounds for which a commercial standard was not available, the quantification was performed through the calibration curve of another compound from the same phenolic group. The results were expressed in $\mu \mathrm{g}$ per $\mathrm{mL}$ of infusion.

\subsection{Statistical analysis}

Three independent samples were analysed for each dose of irradiation with three aqueous extractions performed for each sample, and all the assays were carried out in triplicate $(n=27)$. The results for control (non-irradiated) and irradiated samples were expressed as mean values \pm standard deviation (SD). The results were analyzed using one-way analysis of variance (ANOVA) followed by Tukey's HSD Test with $p=0.05$. In the case of phenolic composition, a Student's $t$-test was used to determine the significant difference among two different samples, with $p=0.05$. When the $p$ value was lower than 0.05 , significant differences between samples were considered. Furthermore, a Pearson's correlation analysis between the antioxidant activity and all the analysed compounds was carried out, with a 95\% confidence level. Analyses were carried out using IBM SPSS Statistics for Windows, version 23.0. (IBM Corp., Armonk, New York, USA).

\section{Results and Discussion}


The results for the total phenolic content and total flavonoid content of infusions prepared from non-irradiated and irradiated samples of T. vulgaris and the evaluation of the antioxidant properties tested by four in vitro assays (DPPH scavenging activity, reducing power, $\beta$-carotene bleaching and lipid peroxidation inhibition) are presented in Table 1. Significantly higher values of total phenolic and flavonoid contents were found in the samples irradiated at $10 \mathrm{kGy}(0.168 \mathrm{mg} \mathrm{GAE} / \mathrm{mL}$ of infusion and $0.06 \mathrm{mg} \mathrm{CE} / \mathrm{mL}$ of infusion, respectively). The increase in total phenolic and flavonoid contents with the irradiation dose could be related with the release of these compounds from the matrix structures, increasing extractability of certain compounds and the degradation of larger compounds into smaller ones (Polovka \& Suhaj, 2010; Taheri, Abdullah, Karimi, Oskoueian \& Ebrahimi, 2014). Statistically significant differences were observed in the $\mathrm{EC}_{50}$ values of all the antioxidant assays among samples subjected to different radiation doses, with $10 \mathrm{kGy}$ leading to the highest antioxidant potential (lowest $\mathrm{EC}_{50}$ values). The increase in the antioxidant capacity of the T. vulgaris samples submitted to $10 \mathrm{kGy}$ is in agreement with previous findings in infusions of irradiated Ginkgo biloba L. (Pereira, Barros, Dueñas, Antonio, Santos-Buelga \& Ferreira, 2015c), Borututu (a folk medicine plant obtained from the African tree Cochlospermum angolense Welw.) (Pereira, Calhelha, Antonio, Queiroz, Barros \& Ferreira, 2014) and ethanolic extracts of Hizikia fusiformis Harvey (edible brown seaweed consumed in Korea and Japan) (Kim et al., 2009).

Table 2 presents data related to the phenolic compounds identification (retention time, $\lambda_{\max }$ in the visible region, pseudomolecular ion, main fragment ions in $\mathrm{MS}^{2}$, and tentative identities) obtained by HPLC-DAD-ESI/MS analysis. The phenolic profile of T. vulgaris infusions revealed the presence of thirteen phenolic compounds, from which seven were phenolic acids derivatives and six were flavonoid glycosides (Table 2). The 
phenolic profile of thyme irradiated with $10 \mathrm{kGy}$ was shown in Figure 1. In this study, the phenolic profile was only evaluated for samples irradiated with the dose of $10 \mathrm{kGy}$, and compared with the control sample; this is because $10 \mathrm{kGy}$ showed higher antioxidant potential comparatively with $1 \mathrm{kGy}$, i.e., lower $\mathrm{EC}_{50}$ values. A similar phenolic profile was previously observed by the authors in methanolic extracts obtained from irradiated samples of T. vulgaris (Pereira et al., 2016). Similarly, Martins, Barros, Santos-Buelga, Silva, Henriques \& Ferreira, (2015) reported apigenin 6,8-di-Cglucoside (peak 2), caffeic acid (3), rosmarinic acid hexoside (6), luteolin-7-Oglucuronide (7), luteolin-7-O-glucoside (8), rosmarinic acid (10), lithospermic acid A (12) and eriodictyol (13) in non-irradiated samples of T. vulgaris. The presence of caffeic acid, luteolin-7-O-glucuronide, rosmarinic acid and eriodictyol was also found in thyme hydrophilic extracts by Fecka \& Turek, (2008), whereas Boros et al. (2010) detected apigenin 6,8-di- $C$-glucoside, caffeic acid, rosmarinic acid and eriodictyol in hydroalcoholic extracts of different Thymus species (T. pannonicus, T. glabrescens, $T$. pulegioides, T. praecox, T. serpyllum).

The majority phenolic compounds found in T. vulgaris infusions were rosmarinic acid hexoside (peak 6), luteolin-7-O-glucuronide (7), caffeic acid trimer (9) and rosmarinic acid (10), as previously found in methanolic extracts of irradiated thyme samples (Pereira et al., 2016). Also, the presence of luteolin-7-O-glucuronide and rosmarinic acid as major compounds in thyme infusions was reported by Martins, Barros, SantosBuelga, Silva, Henriques \& Ferreira, (2015).

In general, gamma radiation at a dose of $10 \mathrm{kGy}$ causes statistically relevant changes in the concentration of the phenolic compounds. Small but significant increases were observed in the levels of methyleriodictyol- $O$-pentosylhexoside, luteolin-7- $O$-glucoside and eriodictyol, and consequently in total flavonoid content. This is in agreement with 
Pereira et al., (2015c) and Alothman, Bhat, \& Karim, (2009) who also observed that irradiation at $10 \mathrm{kGy}$ dose caused an increase in some individual phenolic compounds in the infusions of Ginkgo biloba. These results could be explained by an increase in compounds extractability due to depolymerization and release from cell wall polysaccharides produced by the irradiation process, as stated above. On the contrary, small but statistically significant decreases were produced in the levels of caffeic acid hexoside, quercetin- $O$-glucuronide, rosmarinic acid hexoside, caffeic acid trimer, rosmarinic acid, caffeic acid derivative and lithospermic acid A, after irradiation at 10 kGy, being also, in total phenolic acids and total phenolic compounds. Otherwise, nonsignificant changes were observed in other phenolic compounds, such as apigenin 6,8 di-C-glucoside (peak 2), caffeic acid (peak 3) and luteolin-7-O-glucuronide (peak 7). It could be supposed that phenolic acids have lower stability against gamma irradiation and, therefore, they are degraded to some extent at higher irradiation doses. Thus, radiation may contribute to increase compounds extractability, on the other hand, it may also lead to degradation of some less stable compounds.

In order to try to relate antioxidant capacity and phenolic composition of the samples, correlation factors were obtained between the sums of phenolic acid derivatives, flavonoids and total phenolic compounds. A Pearson's correlation between all antioxidant activities tested was performed, because the normality was verified through a Shapiro-Wilk test. The correlations of all antioxidant assays (DPPH scavenging activity, reducing power, $\beta$-carotene bleaching and lipid peroxidation inhibition) and total phenolic compounds are presented in Table 3. In general, the majority of the compounds showed correlations statistically significant with the antioxidant activity assays. Methyleriodictyol- $O$-pentosylhexoside, luteolin-7- $O$-glucoside and eriodictyol (peaks 4, 8 and 13) presented highly significant correlations with all antioxidant 
activities tested but these correlations were negative, meaning that the antioxidant activity increased (lower $\mathrm{EC}_{50}$ values), for irradiated samples with $10 \mathrm{kGy}$, with increasing concentrations of these compounds at the same dose; therefore, inducing a similar behavior in the total flavonoid content. However, the compounds corresponding to peaks $1,5,7,6,10$ and 12 also revealed statistically significant correlations, presenting $p$-values $<0.05$. Otherwise, apigenin 6,8-di-C-glucoside (peak 2) and caffeic acid (peak 3 ) were the only compounds that did not statistically significantly relate to any of the antioxidant assays, presenting $p$-value $>0.05$. The major individual phenolic compound (peak 6 - rosmarinic acid hexoside) also had a high correlation with all the antioxidant activity assays, showing a variation between 0.815 and 0.865 . Overall, total phenolic acids, total flavonoids and total phenolic compounds showed statistically significant correlations with all assays, displaying $p$-values $\leq 0.05$.

\section{Conclusion}

Infusions are a form of consumption of thyme leaves and evaluation of their bioactive potential depending on the type of plant processing is extremely important. According to the results, it was evident that gamma radiation had an influence on the antioxidant activity of the samples, with treatment at $10 \mathrm{kGy}$ leading to higher antioxidant potential (lower $\mathrm{EC}_{50}$ values in all the assays). This irradiation dose $(10 \mathrm{kGy})$ also evidenced higher total phenolic and flavonoid contents. The composition in phenolic compounds was determined and thirteen compounds were detected in the infusions prepared either from irradiated or non-irradiated samples and, in general, the gamma irradiation treatment at a dose of $10 \mathrm{kGy}$ caused relevant changes in the concentration of several compounds. Methyleriodictyol- $O$-pentosylhexoside, luteolin-7- $O$-glucoside, eriodictyol and total flavonoid content were the only ones that increase with the irradiation dose 
applied (10 kGy), and apigenin 6,8-di- $C$-glucoside, caffeic acid and luteolin-7-Oglucuronide were the only compounds with no statistically significant changes observed. The results show that, for the legally permitted maximum radiation dose in EU (10 kGy), gamma radiation may even improve the antioxidant potential and total flavonoid content of T. vulgaris infusion without changing its chemical profile.

\section{Acknowledgements}

The authors are grateful to the Foundation for Science and Technology (FCT, Portugal) and FEDER under Programe PT2020 for financial support to CIMO (UID/AGR/00690/2013), LSRE (Project UID/EQU/50020/2013), C²TN (RECI/AAGTEC/0400/2012), L. Barros (SFRH/BPD/107855/2015) and R.C. Calhelha (SFRH/BPD/ BPD/68344/2010) grants. The authors are also grateful to Ministry of Agriculture, Portugal (Project AROMAP - PRODER/FEADER/EU), for financial support of the work and E. Pereira grant, and to Pragmático Aroma Lda company for providing the “MaisErvas - Aromáticas e Medicinais" samples.

\section{Conflict of interest}

The authors declare they have no conflict of interest.

\section{References}

Alothman, M., Bhat, R., \& Karim, A.A. (2009). Effects of radiation processing on phytochemicals and antioxidants in plant produce. Trends Food Science and Technology, 20, 201-212. 
Amarowicz, R., Pegg, R.B., Rahimi-Moghaddam, P., Barl, B., \& Weil, J.A. (2004). Free radical scavenging capacity and antioxidant activity of selected plant species from the Canadian prairies. Food Chemistry, 84, 551-562.

ASTM, American Society for Testing and Materials (1992) Practice for using the fricke reference standard dosimetry system, ASTM E1026. Annual Book of ASTM Standards, 12.02, Philadelphia, PA.

Balladin, D.A., \& Headley, O. (1999). Evaluation of solar dried thyme (Thymus vulgaris Linné) herbs. Renewable Energy, 17, 523-531.

Barros, L., Pereira, E., Calhelha, R.C., Dueñas, M., Carvalho, A.M., Santos-Buelga, C., \& Ferreira, I.C.F.R. (2013). Bioactivity and chemical characterization in hydrophilic and lipophilic compounds of Chenopodium ambrosioides L.. Journal of Functional Foods, 5, 1732-1740.

Boros, B., Jakabová, S., Dörnyei, Á., Horváth, G., Pluhár, Z., Kilár, F., \& Felinger, A. (2010). Determination of polyphenolic compounds by liquid chromatographymass spectrometry in thymus species. Journal of Chromatography A, 1217, 79727980.

Brandstetter, S., Berthold, C., Isnardy, B., Solar, S., \& Elmadfa, I. (2009). Impact of gamma-irradiation on the antioxidative properties of sage, thyme, and oregano. Food and Chemical Toxicology, 47, 2230-2235.

Caleja, C., Barros, L., Antonio, A.L., Ciric, A., Soković, M., Oliveira, M.B.P.P., Santos-Buelga, C., \& Ferreira, I.C.F.R. (2015). Foeniculum vulgare Mill. as natural conservation enhancer and health promoter by incorporation in cottage cheese. Journal of Functional Foods, 12, 428-438.

Carvalho, L.M., Costa, J.A.M., \& Carnelossi, M.A.G. (2010). Qualidade em plantas medicinais. Aracaju, SE. Embrapa Tabuleiros Costeiros. pp:56. 
Damianova, S., Tasheva, S., Stoyanova, A., \& Damianov, D. (2008). Investigation of extracts from thyme (Thymus vulgaris L.) for application in cosmetics. Journal of essential oil-bearing plants, 11, 443-450.

EU, 1999. Directive 1999/3/EC of the European Parliament and of the Council of 22 February 1999 on the establishment of a Community list of foods and food ingredients treated with ionising radiation. Official Journal of the European Communities L66/24-L66/25.

Fecka, I., \& Turek, S. (2008). Determination of polyphenolic compounds in commercial herbal drugs and spices from Lamiaceae: thyme, wild thyme and sweet marjoram by chromatographic techniques. Food Chemistry, 108, 1039-1053.

Fernandes, Â., Antonio, A.L., Barreira, J.C.M., Oliveira, M.B.P.P., Martins, A., \& Ferreira, I.C.F.R. (2012). Effects of gamma irradiation on physical parameters of Lactarius deliciosus wild edible mushrooms. Postharvest Biology and Technology, 74, 79-84.

Fernandes, Â., Barreira, J.C.M., Antonio, A.L., Santos, P.M.P., Martins, A., Oliveira, M.B.P.P., \& Ferreira, I.C.F.R. (2013). Study of chemical changes and antioxidant activity variation induced by gamma-irradiation on wild mushrooms: Comparative study through principal component analysis. Food Research International, 54, 1825.

Gavarić, N., Kladar, N., Mišan, A., Nikolić, A., Samojlik, I., Mimica-Dukić, N., \& Božin, B. (2015). Postdistillation waste material of thyme (Thymus vulgaris L., Lamiaceae) as a potential source of biologically active compounds. Industrial Crops and Products, 74, 457-464.

Hayta, S., Polat, R., \& Selvi, S. (2014). Traditional uses of medicinal plants in Elazı $\breve{g}$ (Turkey). Journal of Ethnopharmacology, 154, 613-623. 
Helmy, W.A., Farrag, A.A., \& Hasaballah, A.A. (2015). Chemical composition and biological Activity of aqueous and methanolic extracts of thyme (Thymus vulgaris). International Journal of Advanced Research, 3, 1285-1305.

IAEA (International Atomic Energy Agency). (2002). Dosimetry for food irradiation. technical report series 490, Vienna.

Jia, Z., Tang, M. \& Wu, J. (1999). The determination of flavonoid contents in mulberry and their scavenging effects on superoxide radicals. Food Chemistry, 64, 555-559.

Kausar, T., Akram, K., \& Kwon, J-H. (2013). Comparative effects of irradiation, fumigation, and storage on the free amino acids and sugar contents of green, black and oolong teas. Radiation Physics and Chemistry, 86, 96-101.

Kim, H-J., Choi, J-I., Kim, D-J., Kim, J-H., Chun, B.S., Ahn, D.H., Yook, H.S., Byun, M.W., Kim, M-J., Shin, M-G., \& Lee, J-W. (2009). Effect of ionizing radiation on the physiological activities of ethanol extract from hizikia fusiformis cooking drips. Applied Radiation and Isotopes, 67, 1509-1512.

Martins, N., Barros, L., Santos-Buelga, C., Silva, S., Henriques, M., \& Ferreira, I.C.F.R. (2015). Decoction, infusion and hydroalcoholic extract of cultivated thyme: Antioxidant and antibacterial activities, and phenolic characterization. Food Chemistry, 167, 131-137.

Pereira, C., Barros, L., \& Ferreira, I.C.F.R. (2015a). A Comparison of the nutritional contribution of thirty-nine aromatic plants used as condiments and/or herbal infusions. Plant Foods for Human Nutrition, 70, 176-183.

Pereira, C., Calhelha, R.C., Antonio, A.L., Queiroz, M.J.R.P., Barros, L., \& Ferreira, I.C.F.R. (2014). Effects of gamma radiation on chemical and antioxidant properties, anti-hepatocellular carcinoma activity and hepatotoxicity of borututu. Innovative Food Science and Emerging Technologies, 26, 271-277. 
Pereira, E., Antonio, A.L., Barreira, J.C.M., Barros, L., Bento, A., \& Ferreira, I.C.F.R (2015b). Gamma irradiation as a practical alternative to preserve the chemical and bioactive wholesomeness of widely used aromatic plants. Food Research International, 67, 338-348.

Pereira, E., Barros, L., Dueñas, M., Antonio, A.L., Santos-Buelga, C., \& Ferreira, I.C.F.R. (2015c). Gamma irradiation improves the extractability of phenolic compounds in Ginkgo biloba L.. Industrial Crops and Products, 74, 144-149.

Pereira, E., Barros, L., \& Ferreira, I.C.F.R. (2013). Chemical characterization of Ginkgo biloba L. and antioxidant properties of its extracts and dietary supplements. Industrial Crops and Products, 51, 244-248.

Pereira, E., Pimenta, A.I., Calhelha, R.C., Antonio, A.L., Cabo Verde, S., Barros, L., Santos-Buelga, C., \& Ferreira, I.C.F.R. (2016). Effects of gamma irradiation on cytotoxicity and phenolic compounds of Thymus vulgaris L. and Mentha $x$ piperita L.. LWT - Food Science and Technology doi:10.1016/j.lwt.2016.04.004

Polovka, M., \& Suhaj, M. (2010). The effect of irradiation and heat treatment on composition and antioxidant properties of culinary herbs and spices - A Review. Food Reviews International, 26, 138-161.

Roberts, P.B. (2014). Food irradiation is safe: Half a century of studies. Radiation Physics and Chemistry, 105, 78-82.

Sádecká, J. (2007). Irradiation of spices - a Review. Czech Journal of Food Sciences, $25,231-242$.

Singh, B., \& Datta, P.S. (2010). Effect of low dose gamma irradiation on plant and grain nutrition of wheat. Radiation Physics and Chemistry, 79, 819-825.

Taheri, S., Abdullah, T.L., Karimi, E., Oskoueian, E., Ebrahimi, M. (2014). Antioxidant capacities and total phenolic contents enhancement with acute gamma irradiation 
in Curcuma alismatifolia (Zingiberaceae) leaves. International Journal of Molecular Sciences, 15, 13077-13090.

Wolfe, K., Wu, X., \& Liu, R.H. (2003). Antioxidant activity of apple peels. Journal of Agricultural and Food Chemistry, 51,609-614.

Zhang, J-Y., Wang, Y-Z., Zhao, Y-L., Yang, S-B., Zuo, Z-T., Yang, M-Q., Zhang, J., Yang, W-Z., Yang, T-M., \& Jin, H. (2011). Phytochemicals and bioactivities of Paris species. Journal of Asian Natural Products Research, 13, 670-681. 
Table 1. Total phenolic content, total flavonoid content and in vitro antioxidant properties of infusions prepared from Thymus vulgaris subjected to gamma radiation.

\begin{tabular}{|c|c|c|c|}
\hline Dose (kGy) & 0 & 1 & 10 \\
\hline Total phenolic content (mg GAE/mL of infusion) & $0.138 \pm 0.001 \mathrm{c}$ & $0.150 \pm 0.001 b$ & $0.168 \pm 0.001 \mathrm{a}$ \\
\hline Total flavonoid content (mg CE/ mL of infusion) & $0.048 \pm 0.001 \mathrm{c}$ & $0.053 \pm 0.001 b$ & $0.060 \pm 0.001 \mathrm{a}$ \\
\hline DPPH scavenging activity $\left(\mathrm{EC}_{50}\right.$ value, $\left.\mathrm{mg} / \mathrm{mL}\right)$ & $0.87 \pm 0.05 \mathrm{a}$ & $0.76 \pm 0.02 b$ & $0.66 \pm 0.02 \mathrm{c}$ \\
\hline Reducing power $\left(\mathrm{EC}_{50}\right.$ value, $\left.\mathrm{mg} / \mathrm{mL}\right)$ & $0.48 \pm 0.01 \mathrm{a}$ & $0.43 \pm 0.01 b$ & $0.41 \pm 0.01 \mathrm{c}$ \\
\hline$\beta$-carotene bleaching inhibition $\left(\mathrm{EC}_{50}\right.$ value, $\left.\mathrm{mg} / \mathrm{mL}\right)$ & $1.63 \pm 0.01 \mathrm{a}$ & $1.66 \pm 0.04 \mathrm{a}$ & $1.25 \pm 0.01 b$ \\
\hline TBARS inhibition $\left(\mathrm{EC}_{50}\right.$ value, $\left.\mathrm{mg} / \mathrm{mL}\right)$ & $0.22 \pm 0.01 \mathrm{a}$ & $0.22 \pm 0.01 \mathrm{a}$ & $0.13 \pm 0.01 b$ \\
\hline
\end{tabular}

GAE- Gallic acid equivalents; CE- Catechin equivalents. In each row different letters mean significant differences $(p<0.05)$. 
Table 2. Retention time (Rt), wavelengths of maximum absorption in the visible region $\left(\lambda_{\max }\right)$, mass spectral data, identification and quantification of phenolic compounds in infusion prepared from Thymus vulgaris subjected to gamma irradiation ( $\mu \mathrm{g} / \mathrm{mL}$ of infusion).

\begin{tabular}{|c|c|c|c|c|c|c|c|c|}
\hline \multirow[b]{2}{*}{ Peak } & \multirow{2}{*}{$\begin{array}{l}\text { Rt } \\
(\min )\end{array}$} & \multirow{2}{*}{$\begin{array}{l}\lambda_{\max } \\
(\mathrm{nm})\end{array}$} & \multirow{2}{*}{ 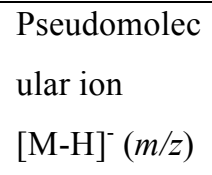 } & \multirow{2}{*}{$\begin{array}{l}\mathrm{MS}^{2} \\
(m / z)\end{array}$} & \multirow[b]{2}{*}{ Tentative identification } & \multicolumn{2}{|l|}{ Infusion } & \multirow{2}{*}{$\begin{array}{l}t \text {-Students test } \\
p \text {-value }\end{array}$} \\
\hline & & & & & & $0 \mathrm{kGy}$ & $10 \mathrm{kGy}$ & \\
\hline 1 & 7.3 & 320 & 341 & $179(100), 135(88)$ & Caffeic acid hexoside & $3.1 \pm 0.1$ & $2.5 \pm 0.2$ & 0.003 \\
\hline 2 & 10.8 & 338 & 593 & $473(20), 383(33), 353(27), 297(5)$ & Apigenin 6,8-di- $C$-glucoside & $6.6 \pm 0.4$ & $6.2 \pm 0.1$ & 0.122 \\
\hline 3 & 11.3 & 326 & 179 & $135(100)$ & Caffeic acid & $4.54 \pm 0.1$ & $4.19 \pm 0.4$ & 0.091 \\
\hline 4 & 17.4 & $284,336 \mathrm{sh}$ & 595 & $301(47), 286(100)$ & Methyleriodictyol- $O$-pentosylhexoside & $5.03 \pm 0.01$ & $6.34 \pm 0.04$ & $<0.001$ \\
\hline 5 & 18.1 & 350 & 461 & $301(100)$ & Quercetin- $O$-glucuronide & $0.21 \pm 0.01$ & $0.13 \pm 0.02$ & 0.002 \\
\hline 6 & 18.8 & 322 & 521 & $359(100), 197(13), 179(36), 161(62), 135(21)$ & Rosmarinic acid hexoside & $33 \pm 1$ & $32 \pm 1$ & 0.035 \\
\hline 7 & 20.0 & 348 & 461 & $285(100)$ & Luteolin-7-O-glucuronide & $24.0 \pm 0.1$ & $23.8 \pm 0.1$ & 0.062 \\
\hline 8 & 20.8 & 350 & 447 & $285(100)$ & Luteolin-7- $O$-glucoside & $4.7 \pm 0.1$ & $5.57 \pm 0.01$ & $<0.001$ \\
\hline 9 & 23.4 & $286,320 \mathrm{sh}$ & 537 & $\begin{array}{l}493(20), 359(70), 295(5), 197(13), 179(28), 16 \\
1(100), 135(63)\end{array}$ & Caffeic acid trimer & $19.36 \pm 0.02$ & $17.8 \pm 0.1$ & $<0.001$ \\
\hline 10 & 24.0 & 330 & 359 & 197(17),179(35),161(100),135(29) & Rosmarinic acid & $22.3 \pm 0.4$ & $21 \pm 1$ & 0.012 \\
\hline 11 & 25.6 & 282 & 567 & $535(23), 493(49), 387(32), 285(25), 197(13)$ & Caffeic acid derivative & $3.0 \pm 0.1$ & $2.6 \pm 0.3$ & 0.034 \\
\hline 12 & 27.5 & $290,326 \mathrm{sh}$ & 537 & 493(50),359(17),295(33),179(75),135(100) & Lithospermic acid A & $3.53 \pm 0.04$ & $2.1 \pm 0.4$ & 0.004 \\
\hline \multirow[t]{4}{*}{13} & 30.6 & $288,334 \mathrm{sh}$ & 287 & $151(35), 135(100)$ & Eriodictyol & $1.51 \pm 0.02$ & $1.6 \pm 0.1$ & 0.019 \\
\hline & & & & & Total phenolic acids & $89 \pm 1$ & $82 \pm 2$ & 0.001 \\
\hline & & & & & Total flavonoids & $42.0 \pm 0.4$ & $43.7 \pm 0.4$ & 0.002 \\
\hline & & & & & Total phenolic compounds & $131 \pm 1$ & $125 \pm 1$ & 0.001 \\
\hline
\end{tabular}


Table 3. Correlation coefficients of phenolic compounds with in vitro antioxidant activity of infusions prepared from Thymus vulgaris subjected to gamma radiation.

\begin{tabular}{|c|c|c|c|c|c|c|c|c|c|}
\hline \multirow[b]{2}{*}{ Peaks } & \multirow[b]{2}{*}{ Compounds } & \multicolumn{2}{|c|}{ DPPH scavenging activity } & \multicolumn{2}{|c|}{ Reducing power } & \multicolumn{2}{|c|}{$\begin{array}{l}\text { B-carotene bleaching } \\
\text { inhibition }\end{array}$} & \multicolumn{2}{|c|}{ TBARS inhibition } \\
\hline & & $\begin{array}{l}\text { Correlation } \\
\text { factor }\end{array}$ & p-value & $\begin{array}{l}\text { Correlation } \\
\text { factor }\end{array}$ & p-value & $\begin{array}{l}\text { Correlation } \\
\text { factor }\end{array}$ & p-value & $\begin{array}{l}\text { Correlation } \\
\text { factor }\end{array}$ & $p$-value \\
\hline 1 & Caffeic acid hexoside & 0.878 & 0.021 & 0.969 & 0.001 & 0.952 & 0.003 & 0.956 & 0.003 \\
\hline 2 & Apigenin 6,8-di- $C$-glucoside & 0.530 & 0.280 & 0.742 & 0.091 & 0.689 & 0.137 & 0.698 & 0.123 \\
\hline 3 & Caffeic acid & 0.719 & 0.107 & 0.724 & 0.104 & 0.750 & 0.086 & 0.742 & 0.091 \\
\hline 4 & Methyleriodictyol- $O$-pentosylhexoside & -0.954 & 0.003 & -0.997 & $<0.001$ & -1.000 & $<0.001$ & -1.000 & $<0.001$ \\
\hline 5 & Quercetin- $O$-glucuronide & 0.945 & 0.004 & 0.962 & 0.002 & 0.965 & 0.002 & 0.967 & 0.002 \\
\hline 6 & Rosmarinic acid hexoside & 0.865 & 0.026 & 0.815 & 0.048 & 0.851 & 0.032 & 0.843 & 0.035 \\
\hline 7 & Luteolin-7-O-glucuronide & 0.679 & 0.138 & 0.817 & 0.047 & 0.778 & 0.068 & 0.788 & 0.063 \\
\hline 8 & Luteolin-7-O-glucoside & -0.926 & 0.008 & -0.998 & $<0.001$ & -0.992 & $<0.001$ & -0.993 & $<0.001$ \\
\hline 9 & Caffeic acid trimer & 0.956 & 0.003 & 0.997 & $<0.001$ & 0.999 & $<0.001$ & 1.000 & $<0.001$ \\
\hline 10 & Rosmarinic acid & 0.906 & 0.013 & 0.890 & 0.017 & 0.916 & 0.010 & 0.911 & 0.012 \\
\hline 11 & Caffeic acid derivative & 0.791 & 0.061 & 0.856 & 0.029 & 0.837 & 0.038 & 0.844 & 0.035 \\
\hline 12 & Lithospermic acid A & 0.906 & 0.013 & 0.941 & 0.005 & 0.953 & 0.003 & 0.950 & 0.004 \\
\hline \multirow[t]{4}{*}{13} & Eriodictyol & -0.808 & 0.052 & -0.885 & 0.019 & -0.887 & 0.018 & -0.884 & 0.011 \\
\hline & Total phenolic acids & 0.945 & 0.004 & 0.961 & 0.002 & 0.975 & 0.001 & 0.972 & 0.001 \\
\hline & Total flavonoids & -0.955 & 0.003 & -0.943 & 0.005 & -0.965 & 0.002 & -0.961 & 0.002 \\
\hline & Total phenolic compounds & 0.940 & 0.005 & 0.964 & 0.002 & 0.977 & 0.001 & 0.974 & 0.001 \\
\hline
\end{tabular}




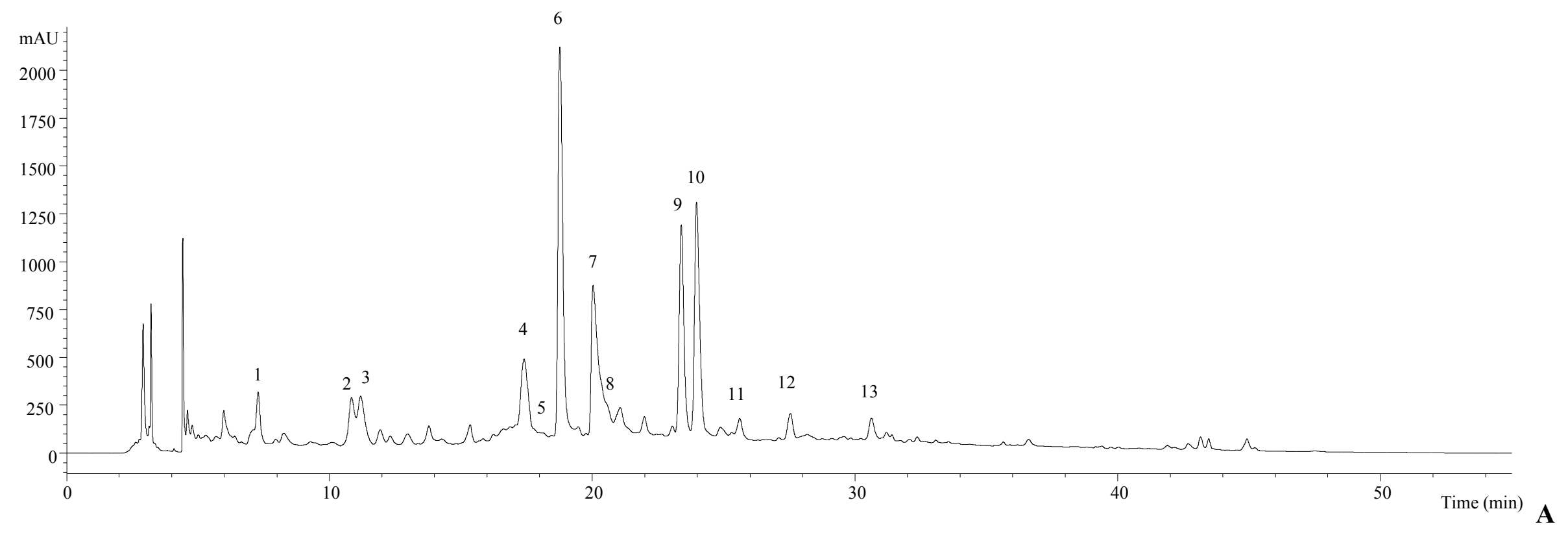




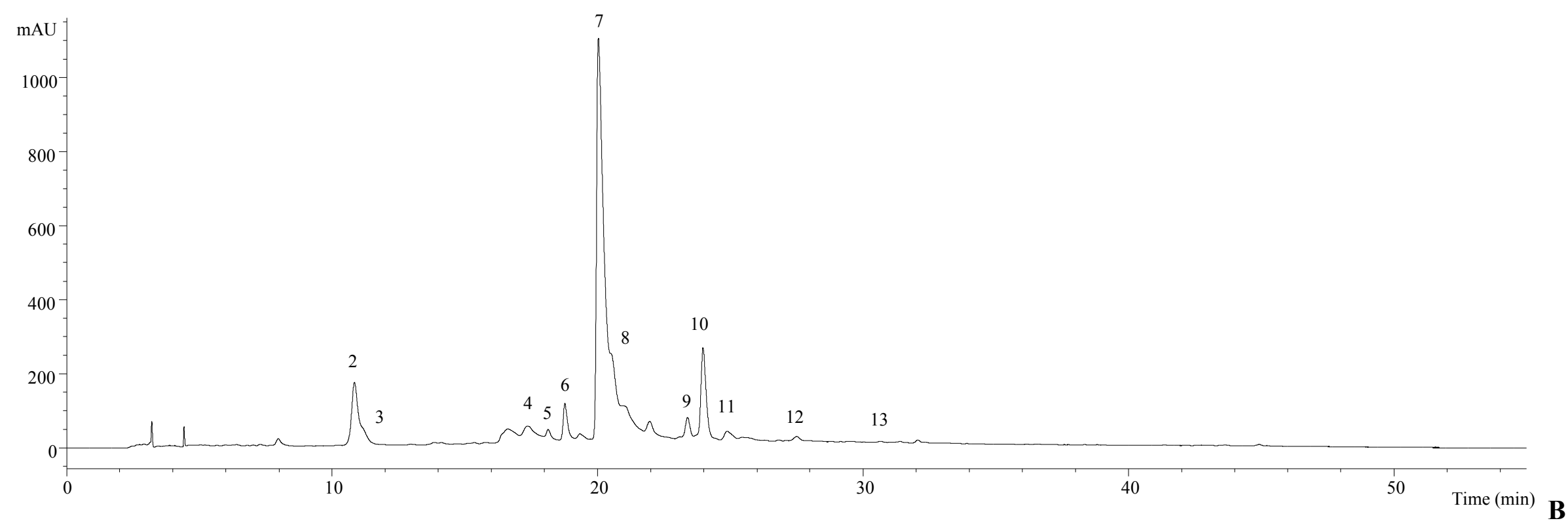

Figure 1. Phenolic compounds profile in infusions prepared from thyme samples irradiated with $10 \mathrm{kGy}$, recorded at $280 \mathrm{~nm}$ (A) and $370 \mathrm{~nm}$ (B). 